\title{
DO TIRAR POLO NATURAL: CONSIDERAÇÕES SOBRE A TEORIA DO RETRATO EM FRANCISCO DE HOLANDA
}

Raphael do Sacramento Fonseca

Aluno da graduação em Artes (com Habilitação em História da Arte) da UERJ.

Retratar é criar monumentos. Buscando o sentido denotativo desta última palavra, encontramos as seguintes definições: "1. Obra ou construção destinada a perpetuar a memória de fato notável ou pessoa ilustre; 2. recordação, memória"1. Logo, todo retrato tem relação direta para com a memória de uma espaço-temporalidade. Erguer este monumento é (re)construir a História, a partir da eternização de um ou mais indivíduos detentores de alguma relevância, visando uma permanência material do objeto-retrato, aporicamente, rumo ao futuro. Como Jacques Le Goff aponta, todo monumento está permeado pela morte, já que, mapeando sua etimologia,

"A palavra latina monumentum remete para a raiz indo-européia men, que exprime uma das funções essenciais do espírito (mens), a memória (memini). O verbo monere significa 'fazer recordar', de onde 'avisar', 'iluminar', 'instruir'. O monumentum é um sinal do passado. Atendendo às suas origens filológicas, o monumento é tudo aquilo que pode evocar o passado, perpetuar a recordação...”. ${ }^{2}$

Objeto de debates desde a Antiguidade, a retratística já se encontrava sintetizada na palavra italiana ritratto em alguns textos do século XIV, sendo problematizada, dentre os dicionários, a partir do século XVI. Segundo Édouard Pommier, inicia-se uma distinção entre imitare (realizar uma imagem à semelhança de alguma coisa) e ritrarre (fazer a cópia literal de algo). Apenas no século XVII, na Espanha e especialmente na Itália, a palavra ganha uma denotação mais próxima da utilizada até os presentes dias: figura cavata dal naturale, ou seja, "figura tirada pelo natural"3 abstração bidimensional realizada a partir do contato direto, "natural", entre retratista e retratado.

${ }^{1}$ FRANCISCO FERNANDES, Celso e PEDRO LUFT, F. Marques Guimarães. Dicionário brasileiro Globo. São Paulo: Globo, 1993, pág. 487.

2 LE GOFF, Jacques. "Documento/monumento" in: História e memória. Campinas: Editora Unicamp, 1996, pág. 535.

${ }^{3}$ POMMIER, Édouard. Theóries du portait - de la Renaissance aux Lumières. Paris: Gallimard, 1998, pág. 17. 
Com uma maior noção de individualidade proporcionada pelo Renascimento, as figuras retratadas começam a ganhar um espaço próprio dentro das obras; já não mais se faz obrigatória a existência de uma cena histórica para se adicionar o corpo de uma pessoa ilustre. A obra pode apenas representá-lo, sem nenhuma justificativa narrativa evidente; a sua presença e seu diálogo para com o espectador já são auto-explicativos. Pope-Henessy irá afirmar que as primeiras experiências formais desses retratos individuais provêm de um espaço de experiência da inserção de retratos de comanditários em pinturas históricas. Logo, fica mais compreensível a hieratização inicial de seus corpos que, pouco a pouco, serão suavizados e realizados com maior destreza, além de um maior detalhamento dos aspectos psicológicos e visuais dos retratados 4 .

Nesse trajeto histórico, diversos foram os teóricos da arte, poetas e artistas que dedicaram algumas linhas à retratística. Contudo, todas estas escritas abordavam questões amplas da prática artística e social, dedicando pouco espaço ao retrato em si. Assim como os retratos individuais precisaram de certo tempo para existir, a reflexão da teoria da arte em torno do retrato e suas especificidades apenas vai ganhar sua primeira abordagem exclusiva em meados do século XVI, precisamente no ano de 1549, com a figura um tanto quanto peculiar de um não-italiano: Francisco de Holanda, português, autor do texto intitulado "Do tirar polo natural".

Trata-se de um consenso para alguns historiadores da retratística, tais como Lorne Campbell e Shearer West, de que o texto seja o primeiro dedicado unicamente à prática do retrato. Porém, mesmo com tal ineditismo na abordagem, a escrita apenas foi se tornar conhecida através de uma primeira impressão realizada por Joaquim de Vasconcelos, no folhetim português "A vida moderna", em 1892. O original manuscrito foi perdido, mas duas cópias suas existem - uma realizada em 1563, em espanhol; outra em português arcaico, de onde Joaquim de Vasconcelos retirou o texto para sua primeira exposição a um grande público. Convém frisar que inexiste qualquer edição crítica apurada do texto. Mesmo sua publicação mais recente, realizada pela editora lisbonense Livros Horizonte, em 1984, carece de aparato crítico - seja quanto às questões relativas à teoria da arte, seja até mesmo ao vocabulário utilizado pelo autor.

Para compreendermos com maior clareza esse certo "esquecimento" tanto do texto, quanto do próprio autor, é importante

\footnotetext{
${ }^{4}$ POPE-HENESSY, John. The portrait in the Renaissance. Nova Iorque: Pantheon Books, 1966, pág. 23.
} 
refletir sobre sua biografia e fortuna crítica. Nascido entre os anos de 1517 e 1518, Francisco de Holanda encontra-se inserido num território sem grande passado nas artes plásticas; um Portugal em que as questões propostas pelos renascentistas italianos se encontram distantes, sendo enxergadas como metas de sua própria produção artística. Os nomes já institucionalizados dos mestres italianos soam como mitos e sua produção se torna paradigmática. Filho de Antônio de Holanda, iluminador e funcionário de D. Manuel no ano de 1518, Francisco cresce na cidade de Évora, ambiente de efervescência cultural, devido à presença da corte desde D. Afonso $\mathrm{V}$, também habitada por outros humanistas portugueses, tais como o escultor Nicolau Chanterene (visto como o renovador da escultura portuguesa) e o poeta André de Resende. Numa política de revitalização das artes, D. João III incentiva a ida de Francisco de Holanda ao território italiano. Este por sua vez o agradece repetidas vezes em seus textos; tomemos como exemplo o prólogo do "Da pintura antigua", que de certa forma resume a intenção da viagem:

"E a Vós, muito Glorioso e Augusto Rei e Senhor, dou eu outras tantas graças pela ajuda que até agora me tem dado (mandando-me ir ver Itália) em bens que, ainda quando se a nau alagasse, e a cidade saqueada estivesse ardendo, eu posso sem impedimento de carga levemente comigo trazer a nado, ou passeando...". 5

Aos vinte anos, o português parte em 1538 e retorna a sua terranatal em 1540. Francisco de Holanda entra em contato com uma série de ilustres personalidades do Renascimento europeu. Fruto direto da viagem é o "Álbum de antigualhas", que consiste, principalmente, em desenhos das antiguidades greco-romanas. Tomando justamente o antigo como juízo de valor, ou seja, quanto mais próxima da Antiguidade a produção artística, quão melhor ela será, Francisco dá forma à sua obra central, o "Da pintura antigua", no ano de 1548. O texto é dividido em duas partes: a primeira, de caráter mais doutrinário, dividida em quarenta e quatro capítulos; a segunda, construída sob a forma de diálogos, dividida em quatro momentos. As escritas possuem uma unicidade de abordagem visível: tratase de uma teoria da arte baseada em fundamentos neoplatônicos, coberta de impressões suas quanto à arte apreciada no território italiano.

O objetivo inicial do texto, a renovação da produção artística em Portugal, a todo instante é reafirmado. Sempre que possível, principalmente

\footnotetext{
${ }^{5}$ HOLANDA, Francisco de. Da pintura antigua. Lisboa: Livros Horizonte, 1984, pág. 16.
} 
em seus "Diálogos em Roma", Francisco de Holanda afirma a superioridade da arte italiana, e até mesmo da francesa, sobre a realizada em Espanha e Portugal. Diversos aspectos são criticados, desde a produção arcaizante portuguesa, que em pleno século XVI ainda bebia das fontes do gótico do norte da Europa, até o estatuto social do pintor que, em Portugal, se assemelhava aos participantes das guildas medievais.

Após o falecimento de D. João III, no ano de 1557, e de D. Sebastião ter subido ao trono, Holanda fica obscurecido; torna-se uma figura ainda mais isolada dentro do território português. Ainda produz mais duas obras, o "Da ciência do desenho" e "Da fábrica que falece a cidade de Lisboa" (ambos de 1571) e "Álbum das idades" (1573), mas logo cai no esquecimento, assim como alguns de seus manuscritos originais. Seu nome vai ser reativado pela historiografia da arte no século XIX, quando maior atenção é dada ao fato de dentre os personagens propostos no "Diálogos em Roma", termos a presença do "divino" Michelangelo. Um longo debate, ainda latente, sobre a autenticidade das palavras que o português coloca em sua boca instaura-se - principalmente no que diz respeito à problemática artística entre Flandres e Itália. Sylvie Deswarte-Rosa, por outra via, irá resgatar a potência do texto de "Da pintura antigua", afirmando que, diferentemente do proposto por Erwin Panofsky em seu "Idea", teria sido Francisco de Holanda o primeiro autor a se apropriar tão objetivamente das teorias neoplatônicas para a produção artística.

Devido a tanta instabilidade, seja devido a questões intrínsecas ao território português, seja às abordagens tradicionais da obra literária e plástica de Holanda, torna-se compreensível o "esquecimento" de seu "Do tirar polo natural". Este se encontra dividido em onze partes, sendo também construído no formato de diálogo, só que entre apenas dois personagens: Fernando (pseudônimo para o próprio autor) e Braz Pereira, suposto amigo de Francisco de Holanda, com quem todo o debate crítico teria efetivamente se dado. Como dito anteriormente, o próprio título do texto está permeado duma concepção mais quinhentista do retrato: figura tirada do natural, pintada através do contato entre retratado e retratista.

O neoplatonismo se faz presente em diversas instâncias do texto, como, por exemplo, quando Fernando afirma que “... se pudera estar o mesmo desenhador só, sem ninguém, e ter na fantasia e memória a pessoa que há-de pôr em obra e pintar, crede que muito melhor seria que tê-la 
diante dos olhos visíveis se a visse com os invisíveis..."6. Tanto melhor será o retrato quanto melhor a Idéia que o permeia. Retratar, para Holanda, é uma possibilidade única, já que, quando é feita, se está a imitar o gesto inicial de Deus:

“... o tratar da pintura é a coisa mais digníssima deste mundo, e o tirar ao natural aquilo que só Deus fez por tão investigabil sabedoria como Ele sabe. Querê-lo um homem de terra imitar deve ser coisa mui grande e a maior que os homens podem fazer; ao menos eu (de o não saber fazer) por maior a estimo; outros tê-lo-ão por menos". ${ }^{7}$

Boa parte dos capítulos estará essencialmente preocupado com detalhes específicos da apreensão do humano através da linguagem plástica. Logo, existem debates quanto à imitação (sempre ideal) dos olhos, do nariz, da boca, enfim, principalmente do rosto humano - parte mais detentora de destaque na retratística. Curiosamente, mesmo com diversos preceitos estabelecidos detalhadamente, os próprios retratos de Francisco de Holanda não fazem correspondência integral. Basta tomarmos como exemplo o "Retrato de Michelangelo", presente em seu "Álbum das Antigualhas".

A indicação de melhor forma de se pintar o rosto, de forma "treçada" (que poderíamos ler como "recursada") e inclinado à mão direita, não está presente; pelo contrário, Holanda realiza o retrato de perfil, forma que ele mesmo critica em seu capítulo "Do escolher o posto e a vista no tirar ao natural": "O meio é muito austero e grave e muito saído para fora, e não mostra nada da fronte nem de diante, mas somente o rigor do perfil"". Ao optar por essa solução formal, o tão necessário "realço nos olhos"10, que Holanda defenderá ao final de sua escrita, também não é perceptível. Nem o traje colocado em Michelangelo tem a fidedignidade que ele prega no capítulo "Do vestido": “... que sempre prometa estar debaixo dele a pessoa escondida e coberta fielmente..."11. No "Retrato de Pietro Lando" encontramos os mesmos problemas de defasagem entre imagem e texto presentes no "Retrato de Michelangelo".

\footnotetext{
${ }^{6}$ HOLANDA, Francisco de. Do tirar polo natural. Lisboa: Livros Horizonte, 1984, pág. 18.

${ }^{7}$ Ibid, pág. 13.

${ }^{8}$ Ibid, pág. 23.

${ }^{9}$ Ibidem.

${ }^{10}$ Ibid, pág. 42.

${ }^{11}$ Ibid, pág. 38.
} 


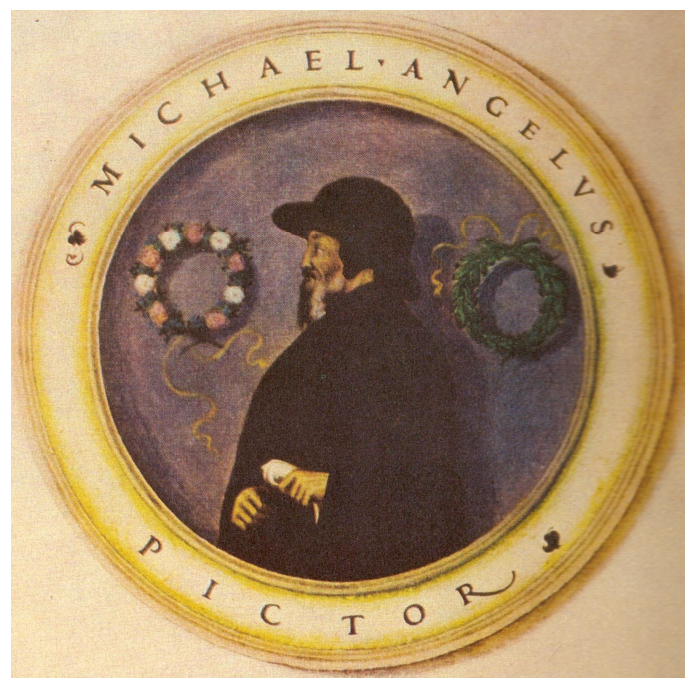

“Retrato de Michelangelo" (1538-1540), por Francisco de Holanda. “Álbum das antigualhas”, Biblioteca do Mosteiro do Escorial.

Ainda assim, uma segunda leitura poderia ser realizada para estas imagens. Partindo do princípio de que Holanda utilizava-se da noção de "antigo" para atribuir qualidades positivas às obras apreciadas, não teria ele querido enquadrar Michelangelo e Pietro Lando num esquema formal arcaizante, semelhante às moedas romanas, possuidoras de retratos de pessoas ilustres? Por outro lado, nos apoiando nessa interpretação, surge como questão o "Retrato do Papa Paulo III", único outro retrato individual ainda existente do português. Provavelmente realizado em Roma, esta pintura nos faz refletir em torno do porquê teria Holanda fugido de seu "esquema romano" de representação - principalmente pelo fato de, por cronologia de sua viagem rumo à Itália, este retrato situar-se entre os de Michelangelo e Pietro Lando.

De qualquer forma, esta é a única de suas obras de retratística que faz correspondência com seus pressupostos escritos. Além de estar composta sobre a forma "treçada", possui certa movimentação de linhas, dadas por seu traje detalhado. Uma maior gama de cores é utilizada e, como Holanda constrói no decorrer de seu texto, a veste representada parece com seu portador; detendo-nos apenas sobre suas vestimentas, conseguimos perceber, que se trata duma figura de alto escalão na hierarquia religiosa. Logo, Holanda consegue algo essencial para sua teoria: dar a posição social 
do retratado em primeira instância, deixando sua verossimilhança facial em segunda. Mesmo assim, o rosto treçado da figura não se encontra inclinado a seu lado direito, mesmo que sua mão direita encontre-se erguida.

Uma questão surge após tais considerações quanto à retratística que permanece de Holanda: se o autor propõe tantos preceitos, mas em suas próprias obras não os concretiza, não estaria ele criando tais linhas a partir da admiração de algum outro pintor? O próprio Holanda nos dá uma resposta possível a essa questão, no capítulo final de seu texto. Braz Pereira o pergunta: "Qual é o mais eminente pintor em pintar retratos ao natural, que vós saibais em Europa, Fernando?”; este responde:

"O mais famoso pintor de retratos que eu estimo haver em cristãos, que são a flor deste mundo, tenho eu que é Ticiano em Veneza, posto que a mim me disse o imperador em Barcelona perante o nosso duque de Aveiro, e perante o duque de Albuquerque, e perante o duque de Alva, que melhor o tirara do natural Antonio d'Ollanda em Toledo, de iluminação, que Ticiano em Bolonha. Porém eu dou vantagem a Ticiano". 12

Não se trata dum isolamento teórico por parte do português; mesmo Giorgio Vasari, que nas suas "Vite" estabelece críticas negativas a Ticiano, em carta de 1547 a Benedetto Varchi, elogia o veneziano enquanto retratista. É sabido que Holanda esteve em Veneza, mas falta exatidão quanto à data. Segundo Sylvie Deswarte-Rosa, sua presença lá se deu em janeiro de 1539, após a eleição de Pietro Lando. Outro problema que surge dessa afirmação de Francisco de Holanda diz respeito aos retratos que Ticiano fez de Carlos V. Teria o autor efetivamente visto algum destes?

Consideremos que Holanda esteve em Barcelona no ano de 1538. Neste momento, Ticiano já havia pintado um retrato de Carlos V em 1533. Assim como Holanda diz em seu texto, este foi realizado em Bolonha. Todas as qualidades propostas por Francisco de Holanda surgem nessa obra: o rosto treçado e à direita, o decoro, a idealização, a adequação do vestuário ao corpo, a iluminação destacada da face, e também a coerência entre a construção monumental da imagem e a posição social de imperador exercida por Carlos V. O suposto retrato iluminado por Antonio de Holanda perdeu-se, impedindo-nos de um confronto entre este e o primeiro retrato de Carlos $\mathrm{V}$ pintado por Ticiano. De qualquer forma, julgamos que a lógica da preferência de Francisco de Holanda pela obra do

\footnotetext{
12 Ibid, pág. 41.
} 
segundo dá-se num viés de construção de um monumento teórico à arte renascentista italiana.

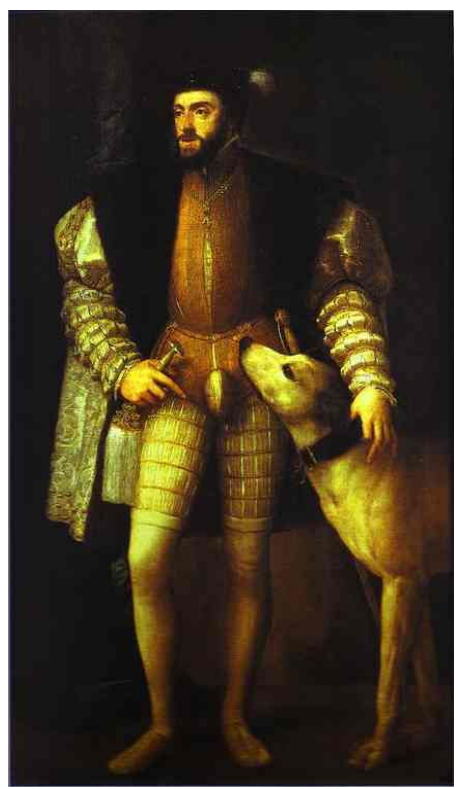

“Retrato de Carlos V” (1533), por Ticiano Vecellio. Museu do Prado.

\begin{abstract}
Além disso, há outra característica que o português atribui aos italianos, que pode ser percebida nessa pintura. Ele diz:
\end{abstract}

"Louvados são em Itália os retratos tirados todos em pé ao natural, e é por mostrar mais do homem. Mas louvam mais as pinturas ou retratos que eles pintam assentados em seus assentos, escolhidos e quietos, ainda que sejam belicosos e armados os príncipes que ao natural são pintados em retrato. E vêse isto ser verdade em a cidade de Florença, que pode em parte ser chamada mãe da pintura, em a obra das sepulturas dos Médicis, que maravilhosamente esculpiu em mármore M. Micael Agnello, pintor famoso, os quais príncipes em seus retratos estão assentados em seus assentos e armados, ou pacíficos. E em outros muitos exemplos da nobilíssima antiguidade poderei provar o que digo em a cidade de Roma". 13

\footnotetext{
${ }^{13}$ Ibid, pág. 36.
} 
Lorne Campbell afirma que este retrato de 1533 trata-se duma releitura de Jakob Seisenegger, que um ano antes havia retratado Carlos V. Daí a inserção, via norte da Europa, de retratos de corpo inteiro na Itália ${ }^{14}$.

A partir desses critérios de avaliação das obras, nos é possível compreender a preferência de Holanda pelas figuras sentadas de Michelangelo. Se Michelangelo é coroado como sendo importante fonte de teorias da arte, além de admirado pela destreza de suas obras com enfoque mais histórico, Ticiano é celebrado como o melhor retratista da vida cortesã. Nesta institucionalização dos dois artistas, temos nas entrelinhas, a constante problemática quinhentista entre disegno e colore.

Também podemos pensar o quanto Holanda teria admirado outro retrato de Carlos V realizado por Ticiano, datado de 1548. Basta termos em mente algumas estátuas eqüestres, como a de Marco Aurélio, inclusive desenhada por Holanda em seu "Álbum das Antigualhas". Já que Ticiano problematiza essa construção clássica dos imperadores, apoiados em seus cavalos, à frente da liderança militar, é crível que Holanda muito provavelmente daria preferência a essa obra, por ser mais "antiquizante" do que a versão plástica anterior proposta por Ticiano.

Com tais considerações a respeito de "Do tirar polo natural", esperamos ter demonstrado a importância do texto, para uma maior compreensão das teorias do retrato que circundavam o ambiente artístico europeu no século XVI. Para tal, é preciso se ter em mente uma perspectiva ampla das obras holandianas, que se encontram em constante relação, além de se levar em consideração os próprios retratos realizados pelo mesmo. Faz-se necessária uma abordagem que não apenas utilize o texto como ponte para reflexões em torno da retratística italiana, mas sim que atribua valores à obra de Francisco de Holanda em si, enquanto potente escrita de uma quase ausente literatura artística portuguesa e enquanto construção teórica que visava um renascimento das artes plásticas lusitanas.

14 CAMPBELL, Lorne. Renaissance portraits: European portrait-painting in the 14th, 15th and 16th Centuries. Londres: Yale University Press, 1990, pág. 234. 


\section{Bibliografia}

ALVES, José da Felicidade. Introdução ao estudo da obra de Francisco de Holanda. Lisboa: Livros Horizonte, 1986.

CAMPBELL, Lorne. Renaissance portraits: European portrait-painting in the 14th, 15th and 16th Centuries. Londres: Yale University Press, 1990.

HOLANDA, Francisco de. Álbum dos desenhos das antigualhas. Lisboa: Livros Horizonte, 1989.

. Da pintura antigua. Lisboa: Livros Horizonte, 1984.

Do tirar polo natural. Lisboa: Livros Horizonte, 1984.

LE GOFF, Jacques. História e memória. Campinas: Editora Unicamp, 1996.

POMMIER, Édouard. Théories du portrait - de la Renaissance aux Lumières. Paris: Gallimard, 1998.

POPE-HENESSY, John. The portrait in the Renaissance. Nova Iorque: Pantheon Books, 1966. 